\title{
Ohra- ja kaurakokoviljasäilörehu emolehmien talvirehuna
}

\author{
Merja Manninen ${ }^{1)}$, Maiju Salin ${ }^{2)}$, Kirsi Saarijärvi ${ }^{3)}$, Lauri Jauhiainen ${ }^{1)}$ ja Seija Jaakkola ${ }^{1)}$ \\ 1)MTT,31600Jokioinen,_merja.manninen@mtt.fi,_lauri.jauhiainen@mtt.fi,seija.jaakkola@mtt.fi \\ 2) HY, 00014 Helsingin yliopisto, maiju.salin@,helsinki.fi \\ 3) MTT, 71750 Maaninka, kirsi.saarijarvi@mtt.fi
}

\begin{abstract}
Johdanto
Kokoviljasäilörehu on varteenotettava vaihtoehto emolehmien talvikauden ruokintaan. Ruokinnan suunnittelua hankaloittaa kuitenkin se, että rehun energiapitoisuudelle ei ole täysin luotettavaa määritysmenetelmää, mikä korostuu rajoitetulla ruokinnalla. Kokoviljasäilörehulla on kuitenkin monia etuja: suuret sadot, työmenekin väheneminen ja tasoittuminen, nurmirehun korjuukaluston hyödyntäminen, hyvä nurmen suojakasvi, puristenesteen vähyys, rehun jäätymättömyys, tukipolitiikka ja siemenrikkaruohojen leviämisen estäminen (Joki-Tokola 1999, Jaakkola 2000). Kokoviljasäilörehun vapaa syöttö ei ole perusteltua täysikasvuisille, hyväkuntoisille emolehmille (Manninen 2001). Rajoitetusti tarjottuna ongelmaksi voi muodostua rehuannoksen määrä, jolloin eläimet käyttävät syömiseen vain muutaman tunnin (Manninen ym. 2002a). Ohrakokoviljasäilörehu on osoittautunut emolehmillä nurmisäilörehun veroiseksi rehuksi ja ruokinta sillä voidaan toteuttaa tasaruokintana (Manninen ym. 2002b). Tämän tutkimuksen tavoitteena oli selvittää ohra- tai kaurakokoviljasäilörehun tuotantovaikutukset täysikasvuisilla emolehmillä. Vertailurehuna oli sulavuudeltaan hyvä esikuivattu nurmisäilörehu.
\end{abstract}

\section{Aineisto ja menetelmät}

\section{Eläinaines ja tuotanto-olosuhteet}

Kokeessa oli 48 täysikasvuista hf-emoa, jotka olivat syntyneet vuonna 1994 (30), 1996 (12) ja 1997 (6). Emot olivat kantavina hf-sonneille Koskis Noak (24) ja Thorsvik Kentauri (24). Koe alkoi 22.11.2000, laidunkausi 29.5.2001 ja koe päättyi 5.9.2001. Talvikauden emot olivat kuudessa, pintaalaltaan lähes samankokoisessa ulkotarhassa, 8 eläintä/tarha. Jokaisessa tarhassa oli kolmiseinäinen katettu ja kuivitettu tuuli- ja makuusuoja eläimille.

\section{Rehut ja ruokinta}

Rehuna oli joko esikuivattu nurmisäilörehu (N), ohrakokoviljasäilörehu $(\mathrm{O})$ tai kaurakokoviljasäilörehu (K). Arve-ohra kylvettiin nurmen suojaviljaksi ja korjattiin kokoviljasäilörehuksi Luoko-Junkkari kaksoissilppurilla taikinatuleentumisasteella 3.-5.8.2000. Veli-kaura kylvettiin nurmen suojaviljaksi ja korjattiin kokoviljasäilörehuksi Elho-kaksoissilppurilla taikinatuleentumisasteella 14.-19.8.2000. O- ja K-rehujen säilöntäaineena oli AIV 10 Plus-liuos 5 1/t ja ne varastoitiin laakasiiloihin. N:n raakaaineena oli timotei-nurminata-apila-seos (65-30-5\%). Kasvusto kaadettiin niittomurskaimella ja korjattiin Ylö-tarkkuussilppurilla 13.-15.6.2000. Rehu säilöttiin AIV 2 Plus -liuoksella 5 1/t ja varastoitiin aumaan. Eläimet ruokittiin lypsylehmien energiasuositusten (Tuori ym. 2000) mukaan siten, että N:n energia-arvo perustui orgaanisen aineen (OA) in vitro -sellulaasisulavuuteen ollen 1,00 RY/kg KA. O:lle ja K:lle käytettiin samalla menetelmällä määritettyä energiapitoisuutta ollen $0,85 \mathrm{RY} / \mathrm{kg} \mathrm{KA}$. Rehuannosta nostettiin $60 \mathrm{~d}$ ennen poikimista ja poikimisen jälkeen vastaamaan $10 \mathrm{~kg}: \mathrm{n}$ maitotuotosta. Eläimet saivat sisäruokintakaudella P-kivennäistä, joka vaihdettiin ennen laidunkautta Mgkivennäiseen. Vitamiinia annettiin ohjeen mukaan. Rehuista analysoitiin KA, tuhka, raakavalkuainen (RV), NDF-kuitu (Van Soest ym. 1991) ja OA:n in vitro -sellulaasisulavuus (Friedel 1990). Rehujen sulavuudet määritettiin emoilla kokeen aikana kahdesti Acid Insoluble Assh -merkkiainemenetelmällä (Anon 1971). Ennen vieroitusta vasikat eivät saaneet väkirehua laitumella.

\section{Eläinten punnitukset, kuntoluokitukset, poikimisten seuranta ja maidontuotannon mittaus}

Emot punnittiin kokeen alkaessa, laitumelle laskettaessa ja kokeen päättyessä kahtena peräkkäisenä päivänä, ennen poikimista (1-7 d) ja poikimisen jälkeen $(<48 \mathrm{~h}$ poikimisesta) kerran. Emot kuntoluokitettiin (Lowman ym. 1976) punnitusten yhteydessä, poikiessa kerran. Vasikat punnittiin välittömästi syntymän jälkeen, 14, 50 ja $100 \mathrm{~d}$ iässä, laitumelle laskettaessa ja kokeen päättyessä. Poikimisen arvostelu tapahtui asteikolla 1-4. Maidontuotanto mitattiin 6 emolta/käsittely viidesti (7, 21, 35, 49 ja 63 d poikimisesta) konelypsymenetelmällä (Manninen ja Huhta 2001). Maitonäytteistä määritettiin 
Valion Lapinlahden aluelaboratoriossa KA-, rasva-, valkuais- ja laktoosipitoisuus Milcoscan FT-6000 FOS infrapuna-analysaattorilla STIR-menetelmällä ja ureapitoisuus Seralyser -fotometrillä.

\section{Laiduntaminen}

Laidunlohkot olivat 1-3 -vuotisia nurmia maalajina karkea hieta. Laidun lannoitettiin 3 kertaa kesässä ja N-lannoituksen määrä oli keskimäärin $165 \mathrm{~kg} / \mathrm{ha}$. Puhdistusniitot tehtiin 3 kertaa laidunkauden aikana. Laidunkaudeksi emot jaettiin kahteen keskenään yhdenmukaiseen astutusryhmään. Laiduntamisen aikana ryhmien laitumet pidettiin tasavertaisessa (alueen koko, massa) kunnossa. Laidunpinta-ala oli alkukesällä 0,48 ja loppukesällä 0,62 ha/emo-vasikka -pari. Alueilta mitattiin lohkon vaihdon yhteydessä alku- ja loppukorkeudet nurmitikulla hylky- ja lakokohdat erottaen, tehtiin massamääritys ja otettiin näyte, josta määritettiin OA:n sulavuus, tuhka ja N.

\section{Tilastollinen käsittely}

Eläinten kunto, paino ja maitotuotos mitattiin kokeen aikana useamman kerran. Samasta eläimestä eri aikoina tehdyt mittaukset ovat korreloituneita. Havaintojen korrelaatiorakennetta tutkittiin analysoimalla aineisto käyttäen erilaisia biologisesti mielekkäitä rakenteita. Rakenteista valittiin sopivin käyttäen Akaiken informaatiokriteeriä (Wolfinger 1996). Käytetty malli oli seuraava:

$$
\mathrm{y}_{\mathrm{ijk}}=\mu+\text { käsittely }_{\mathrm{i}}+\text { karsina }_{\mathrm{j(i)}}+\text { eläin }_{1(\mathrm{j})}+\text { aika }_{\mathrm{k}}+\text { aika×käsittely }_{\mathrm{ik}}+{\text { kasina } \times a i k a_{\mathrm{kj}(\mathrm{i})}}+\varepsilon_{\mathrm{ijk}}
$$

missä käsittely ${ }_{i}$, aika $a_{k}$ ja aika×käsittely ${ }_{i k}$ ovat ruokinnan ja mittausajankohdan pää- ja yhdysvaikutukset. Vastaavasti $\operatorname{karsina}_{\mathrm{j}(\mathrm{i})}$, $\operatorname{kasina} \times \mathrm{aika}_{\mathrm{kj( \textrm {i }})}, \varepsilon_{\mathrm{ijk}} \mathrm{ja}$ eläin $_{1(\mathrm{j})}$ ovat normaalijakautuneita satunnaisvaikutuksia. Vasikoiden painot analysoitiin kahdessa osassa: ikään liittyvät päivät $(1,14,50,100$ ja 167 d syntymästä) ja kokeen kulkuun liittyvät päivät (laitumelle lasku ja kokeen loppu). Analyyseissä malliin lisättiin kovariaattina syntymäpäivä ja sukupuoli. Lisäksi sallittiin, että sukupuolten välinen ero voi muuttua eläinten vanhetessa. Ne ominaisuudet, jotka oli mitattu vain kerran, analysoitiin käyttäen mallin alkuosaa $\left(=\mu+\right.$ käsittely $_{\mathrm{i}}+$ karsina $_{\mathrm{j}(\mathrm{i})}+$ eläin $\left._{1(\mathrm{j})}\right)$. Aineistot analysoitiin SAS-ohjelmiston MIXED-proceduurilla (SAS 1999). Mallin aineistoa koskevat oletukset (mm. normaalisuus ja vakiovarianssioletus) tarkastettiin tutkimalla jäännöksiä graafisesti box-plot-kuviolla (Neter ym. 1996).

\section{Tulokset ja tulosten tarkastelu}

Ajanjakso kokeen alusta poikimiseen oli 119 ja poikimisesta laitumelle 68 d. Laidunkausi oli $99 \mathrm{~d}$. Yksi N-vasikka menetettiin poikimisen yhteydessä tukehtumisen johdosta. Yksi O-emo todettiin tyhjäksi, toinen O-emo poiki heikon vasikan ja kolmas O-emo-vasikka -pari poistettiin poikimisen jälkeen ilmenneen prolapsian johdosta. Yksi K-emo todettiin tyhjäksi ja toinen K-emo poiki ennenaikaisesti ja teurastettiin ennen laidunkautta. Muilta osin emojen ja vasikoiden terveys oli hyvä.

N:n KA-pitoisuus oli keskimäärin 239, O:n 299 ja K:n 311 g/kg. In vitro/in vivo -sulavuuksiin perustuvat D-arvot olivat vastaavasti $72,2 / 69,9 \%, 66,7 / 68,0 \%$ ja $64,0 / 61,3 \%$. RV:sta rehut sisälsivät 192, 110 ja 92 g/kg KA, NDF-kuitua 478, 465 ja 497 g/kg KA ja pH oli 3,97, 4,12 ja 3,99. Energiaarvot olivat $0,99 / 0,96,0,88 / 0,90$ ja $0,85 / 0,81 \mathrm{RY} / \mathrm{kg} \mathrm{KA}$. Säilönnällinen laatu oli moitteeton, mutta voihappoa $\mathrm{O}$ ja K rehut sisälsivät 5,7 ja $1,7 \mathrm{~g} / \mathrm{kg}$ KA. O- ja K-emojen syönti oli talvikaudella N-emoja suurempi (Taulukko 1). Rehu ei vaikuttanut eläinten elopainoon (Taulukko 2). Talvikauden aikana Kemot menettivät elopainoaan merkitsevästi enemmän kuin O-emot ( $<<0,01,56,3$ vs. 8,8 kg), myös ero N-emoihin oli merkitsevä ( $\mathrm{p}<0,05,56,3$ vs. 19,0 kg). Kokeen aikana kaikkien emojen elopaino lisääntyi, N-emojen hieman enemmän kuin K-emojen ( $\mathrm{p}<0,10,81,5$ vs. 55,4 kg). Laidunkauden alkaessa Kemojen kunto oli heikompi kuin $\mathrm{N}$ - ja O-emojen, mutta kaikilla ajankohtaan nähden erinomainen. Talven aikana K-emot menettivät kuntoaan merkitsevästi $\mathrm{N}$ - ja O-emoja enemmän ( $\mathrm{p}<0,001,-0,39$ vs. 0,23 ja 0,09), mutta kuntoutuivat laidunkaudella hyvin ( $<<0,01,0,90$ vs. 0,47 ja 0,38 ). K-emojen maidontuotanto oli N-emoja niukempaa (Taulukko 3). Ureapitoisuus oli N-maidossa O- ja K-maitoa suurempi johtuen todennäköisesti N-emojen rehun suuremmasta RV-pitoisuudesta. Poikimiskausi ajoittui ajalle 22.2.-14.4.2001. Poikimiset olivat helppoja lukuun ottamatta emoa, jolle tuli prolapsia. Sisällä vasikat kasvoivat keskimäärin 1122, laitumella 1519 ja kokeen aikana 1357 g/d (Taulukko 4). Kokeen päättyessä vasikat olivat keskimäärin $167 \mathrm{~d}$ ja $271 \mathrm{~kg}$. 
Laitumien sato oli keskimäärin $2300 \mathrm{RY} / \mathrm{ha}$. Laitumen mitoitus oli melko runsas, mikä näkyy korkeina syötyjen alojen loppukorkeuksina. Tämän seurauksena emot kuntoutuivat hyvin ja vasikat kasvoivat erinomaisesti, mutta ry-sato jäi alhaiseksi. Keskikesällä massat ja alkukorkeudet nousivat hieman laidunlohkoa vaihdettaessa. Syötyjen alojen loppukorkeus oli keskikesällä 9,3-14,4 cm. Keskikesällä laitumen RV-pitoisuus laski selvästi alle $20 \%$, samaan aikaan D-arvo pysyi noin $70 \%$. Heikosti syötyjen alojen osuus vaihteli heikkolaatuisen ruohon aikana välillä 8-48 \%, mikä heijasti eläinten vaihtelevaa syöntikäyttäytymistä. Keskimäärin koko laidunkauden aikana laidunlohkoa vaihdettaessa ruohon D-arvo oli 72,0 \% (sd 4,14), RV-pitoisuus 18,9 \% (sd 3,68), alkukorkeus 37,7 cm (sd 13,1) ja syötyjen alojen korkeus $12,0 \mathrm{~cm}$ (sd 1,23). Heikosti syötyjen alojen osuus oli koko laidunkauden aikana keskimäärin 11,9 \%. Astutuskauden (6.6.-3.9.2001) aloittaneista, koko talven kokeessa olleista 42 emosta kaikki tiinehtyivät keskimäärin 89 d poikimisesta. Poikimisväli määritettiin 38 emolle ollen $376 \mathrm{~d}$.

Taulukko 1. Emojen syönti ja ravintoaineiden saanti (In vitro / In vivo).

\begin{tabular}{|c|c|c|c|c|c|c|c|}
\hline Rehu & $\mathrm{N}$ & $\mathrm{O}$ & $\mathrm{K}$ & SEM $^{1}$ & $\mathrm{~N} v s . \mathrm{O}$ & $\mathrm{N} v s . \mathrm{K}$ & $\mathrm{O} v s . \mathrm{K}$ \\
\hline KA kg, Säilörehu & 9,07 & 10,37 & 10,17 & 0,052 & $* * *$ & $* *$ & \\
\hline Kivennäinen & 0,10 & 0,10 & 0,10 & 0,003 & & & \\
\hline Yhteensä & 9,16 & 10,47 & 10,27 & 0,052 & $* * *$ & $* *$ & \\
\hline $\mathrm{OA}, \mathrm{kg}$ & 8,40 & 9,88 & 9,67 & 0,049 & $* * *$ & $* * *$ & \\
\hline Raakavalkuainen, g & 1728 & 1133 & 935 & 9,1 & $* * *$ & $* * *$ & $* *$ \\
\hline RY & $8,93 / 8,67$ & $9,12 / 9,34$ & $8,61 / 8,25$ & $0,050 / 0,049$ & / ** & $* / *$ & $* / * *$ \\
\hline OIV, $\mathrm{g}$ & $810 / 792$ & 834 / 849 & $775 / 749$ & $4,5 / 4,4$ & $\mathrm{o} / * *$ & $* / *$ & $* * / * *$ \\
\hline Sulava OA & $6,55 / 6,34$ & $6,90 / 7,05$ & $6,51 / 6,23$ & $0,037 / 0,036$ & $* / * *$ & & $* * / * *$ \\
\hline
\end{tabular}
o $\mathrm{p}<0,10 ; * \mathrm{p}<0,05 ; * * \mathrm{p}<0,01 ; * * * \mathrm{p}<0,001 .{ }^{1}$ Keskiarvon keskivirhe.

Taulukko 2. Ruokinnan vaikutus emojen elopainoon (kg) ja kuntoluokkaan (kl).

\begin{tabular}{|c|c|c|c|c|c|c|}
\hline Rehu & $\mathrm{N}$ & $\mathrm{O}$ & $\mathrm{K}$ & $\mathrm{N} v s . \mathrm{O}$ & $\mathrm{N} v s . \mathrm{K}$ & $\mathrm{O} v s . \mathrm{K}$ \\
\hline Eläinten lukumäärä & $16^{a}$ & $15^{\text {ad }}$ & $15^{\text {axd }}$ & & & \\
\hline Poikimispäivä $^{2}$ & 81 & 81 & 78 & $3,6-3,7$ & & \\
\hline$K g$, Alussa & 741 & 737 & 744 & $20,1-20,8$ & & \\
\hline $60 \mathrm{~d}$ ennen poikimista & 776 & 778 & 768 & $21,5-22,2$ & & \\
\hline Ennen poikimista & 825 & 821 & 796 & $21,1-21,8$ & & \\
\hline Poikimisen jälkeen & 762 & 750 & 729 & $21,8-22,6$ & & \\
\hline Laidunkauden alk. & 722 & 728 & 687 & $19,6-20,4$ & & \\
\hline Kokeen päättyessä & 822 & 805 & 799 & $20,5-21,3$ & & \\
\hline$K l$, Alussa & 3,19 & 3,24 & 3,25 & $0,062-0,064$ & & \\
\hline $60 \mathrm{~d}$ ennen poikimista & 3,27 & 3,27 & 3,22 & $0,059-0,061$ & \multirow{4}{*}{$* * *$} & \multirow{4}{*}{$* *$} \\
\hline Poikiessa & 3,17 & 3,18 & 3,07 & $0,070-0,073$ & & \\
\hline Laidunkauden alkaessa & 3,42 & 3,32 & 2,86 & $0,086-0,090$ & & \\
\hline Kokeen päättyessä & 3,89 & 3,70 & 3,75 & $0,118-0,125$ & & \\
\hline
\end{tabular}

Taulukko 3. Ruokinnan vaikutus maidontuotantoon (kg) ja maidon koostumukseen (g/kg).

\begin{tabular}{|c|c|c|c|c|c|c|c|}
\hline Rehu & $\mathrm{N}$ & $\mathrm{O}$ & $\mathrm{K}$ & $\mathrm{SEM}^{1}$ & $\mathrm{~N} v s . \mathrm{O}$ & $\mathrm{N} v s . \mathrm{K}$ & $\mathrm{O} v s . \mathrm{K}$ \\
\hline Maitoa keskimäärin, kg & 11,4 & 10,3 & 9,5 & 0,56 & & $*$ & \\
\hline Rasva & 39,8 & 37,4 & 38,8 & 1,83 & & & \\
\hline Valkuainen & 32,2 & 32,6 & 31,8 & 0,91 & & & \\
\hline Laktoosi & 49,1 & 50,7 & 49,3 & 0,53 & o & & $\mathrm{o}$ \\
\hline Urea, mg/100 ml & 31,3 & 21,1 & 18,1 & $1,55-1,57$ & $* * *$ & $* * *$ & \\
\hline Kuiva-aine & 127,0 & 126,5 & 126,0 & 1,83 & & & \\
\hline
\end{tabular}

$\mathrm{o} \mathrm{p}<0,10 ; * \mathrm{p}<0,05 ; * * \mathrm{p}<0,01 ; * * * \mathrm{p}<0,001 . \quad{ }^{1}$ Keskiarvon keskivirhe. 
Taulukko 4. Emän ruokinnan vaikutus vasikoiden kehitykseen.

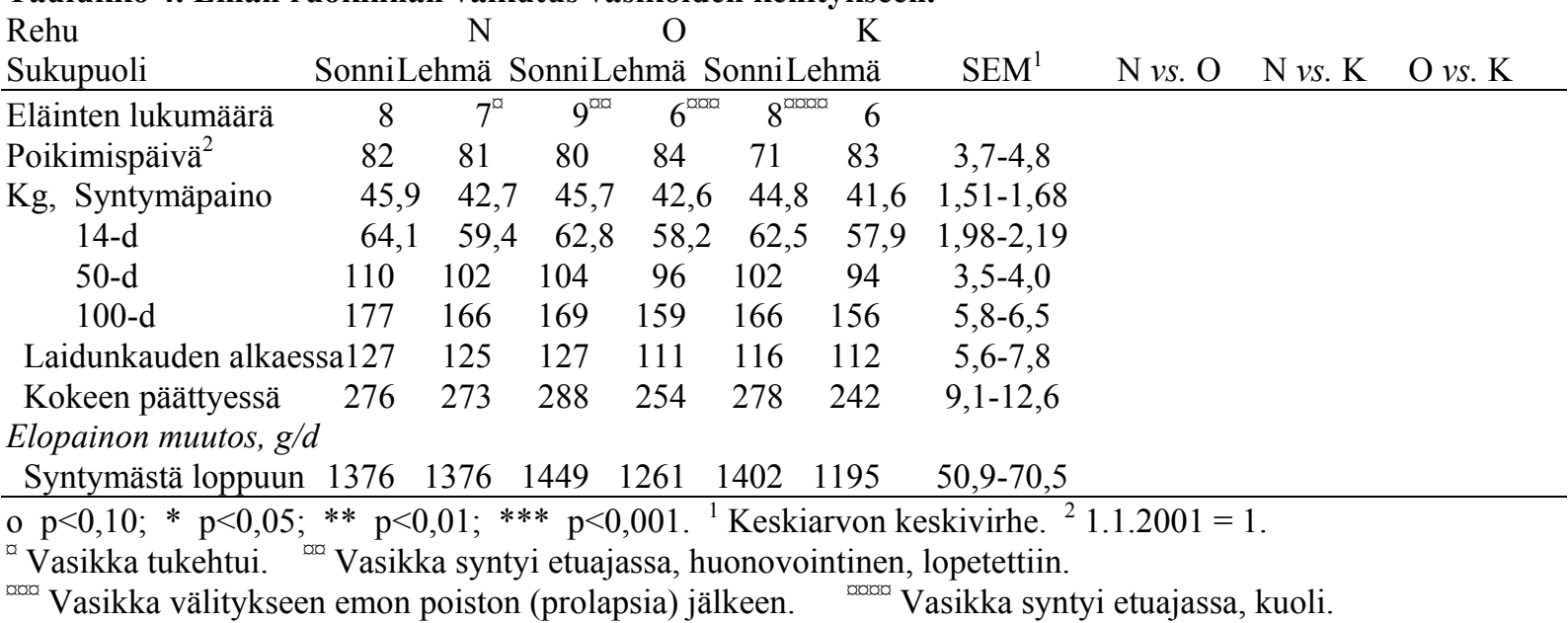

\section{Johtopäätökset}

Kaikki emot olivat hyväkuntoisia koko kokeen ajan, mikä osaltaan selittää tuloksia mm. eläinten kunnon ja elopainon osalta. Kaurasta tehty kokoviljasäilörehu oli energiapitoisuudeltaan ohrakokoviljasäilörehua heikompaa, mutta riitti erinomaisesti täyttämään hyväkuntoisten emojen energia- ja valkuaistarpeen. Niukemmin energiaa sisältävä kaurakokoviljasäilörehu sopii emojen talvikauden rehuksi jopa ohrakokoviljasäilörehua paremmin. Ennen poikimista kokoviljasäilörehu yhdessä esim. oljen kanssa voi olla hyvä rehustusvaihtoehto takaamaan riittävästi energiaa ja tarpeeksi syötävää emoille.

\section{Kiitokset MTT:n emolehmänavetan EMO-tiimille kokeen toteutuksesta ja eläinten hyvästä hoidosta.}

\section{Kirjallisuus}

Anon, 1971. Determination of ash which is insoluble in hydrochloric acid. Method B. Official Journal of European Community, 2155/13:30-31.

Friedel, K. 1990. Die Schätzung des energetischen Futterwertes von Grobfutter mit Hilfe einer Cellulasemethode. [The estimation of the energetic feeding value of roughages by means of cellulase method]. Wissenschaftliche Zeitung Universitet Rostock, N-Reihe 39, 78-86.

Jaakkola, S. 2000. Kokoviljasäilörehusta lupaavia tuloksia. Nauta 2:16-18.

Joki-Tokola, E. 1999. Kokoviljasäilörehu nautakarjantilan viljelykierrossa. In: Agro Food '99, 4.2.1999. E 52.

Lowman, B.G., Scott, N.A. \& Sommerville, S.H. 1976. Condition Scoring of Cattle.The East of Scotland College of Agriculture. Animal Production, Advisory and Development Department. Bulletin No.6. 31p.

Manninen, M. 2001. Ohrakokoviljasäilörehua emolehmille vapaasti? Loppuraportti: Hyvinvoivat naudat puhtaassa ympäristössä 2001: 24-30.

Manninen, M. \& Huhta, H. 2001. Influence of pre partum and post partum plane of nutrition on the performance of crossbred suckler cows and their progeny. Agr. Food Sci. Finl. 10: 3-18.

Manninen, M., Järvenranta, K. \& Virkajärvi, P. 2002a. Ohrasta tehty kokoviljasäilörehu emolehmien talvikauden rehuna. In: Maataloustieteen päivät 9-10.1.2002. Kotieläintiede. p. 184-187.

Manninen, M., Salin, M., Jauhiainen, L., Jaakkola, S. \& Järvenranta, K. 2002b. Ohrasta tehty kokoviljasäilörehu emolehmien talvikauden rehuna tasaisella ja porrastetulla ruokintamenetelmällä. In: Maataloustieteen päivät 9-10.1.2002. Kotieläintiede. p. 180-183.

Neter, J., Kutner, M., Nachtsheim C. \& Wasserman, W., 1996. Applied Linear Statistical Models, Fourth Edition. Irwin, Chicago, $1310 \mathrm{pp}$.

SAS. 1999. SAS/STAT User's Guide, Version 8, Cary, NC: SAS Institute Inc. 3809 p.

Tuori, M., Kaustell, K., Valaja, J., Aimonen, E., Saarisalo, E. ja Huhtanen, P. 2000. Rehutaulukot ja ruokintasuositukset. Helsinki. 99p.

Van Soest, P.J., Robertson, J.B. \& Lewis, B.A. 1991. Methods for dietary fiber, neutral detergent fiber and nonstarch polysaccharides in relation to animal nutrition. J. Dairy Sci. 74: 3583-3597.

Wolfinger, R., 1996. Heterogeneous Variance-Covariance Structures for Repeated Measures. Journal of Agricultural, Biological, and Environmental Statistics, Volume 1, Number 2: 205-230. 